\title{
Cultivation of Aesthetic Feeling in Music Teaching Class of Primary and Middle Schools
}

\author{
Ying-Ying XIAN ${ }^{1, a}$, Dong-Ni SUN ${ }^{2}$, \\ ${ }^{1}$ School of Art and Media, Bohai University, Jinzhou, China \\ ${ }^{2}$ School of Art and Media, Bohai University, Jinzhou, China \\ axianyingying1980@126.com
}

\begin{abstract}
Keywords: Aesthetic Experience, Aesthetic Feeling, Music Aesthetic Feeling.
\end{abstract}
\begin{abstract}
With the continuous development of music aesthetic education in primary and middle schools in China, higher requirements have been put forward on the students' music aesthetic feeling education according to the talent development concept of the $21^{\text {st }}$ century.Music aesthetic education is not only an important organic part of our education system, but also the key point for the implementation of student music aesthetic quality education. In nowadays, more comprehensive music basis of students are required, and the situation emphasizing on students' music technology training previously has been changed, and instead more attentions are paid on students' life and interest, hoping that students could receive aesthetic joy, emotional resonance, as well as soul purification through the music aesthetic feeling learning, to increase interest on music aesthetic and particularly cultivate the ability of music aesthetic feeling, and to make students love music, art and life form the heart. Therefore the music aesthetic experience is the most important part of music courses. However, on the cultivation ways for students' aesthetic experience of music, it is still not so distinct with the old and traditional education system, which was analyzed in this paper from the following three aspects: Firstly, theory on origin of music aesthetic feeling was elaborated to provide theoretical basis for the forming of music aesthetic ability; Secondly, auditory sense of music is proved to be an important part of the cultivation of music aesthetic feeling of students in classroom teaching; Thirdly, Considering to the input and output ways of music aesthetic feeling cultivation, it should be a complete and systematic process of the students' aesthetic feeling cultivation on music, during which the students should accept the external music rendering, and simultaneously make expression of music appropriately, so as to impress students the emotional touch of music and deepen the students' musical experience, with the aim to incarnate the value of music aesthetic feeling cultivation.
\end{abstract}

\section{Introduction}

The core concept of aesthetic experience emphasizes cultivation of students' aesthetic feelings actively and improvement on their aesthetic ability by listening, performance and other creative experience activities. The ultimate goal of aesthetic education is to create a perfect personality, and the way of education is to create a perfect personality, and the way of education combines beauty of art and reality. For the acquisition of aesthetic experience, to a certain extent, it must be through the way of aesthetic feeling. Good aesthetic experience is the important part of aesthetic learning, critical foundation for the whole aesthetic learning, and also a crucial way to cultivate students' aesthetic experience and help students acquire aesthetic ability. The acquisition of aesthetic feeling could greatly enrich students' emotional experience, improve their cultural connotation, and promote the healthy development of physics and mentality.

\section{The Source of Music Aesthetic Experience}

In recent years, music education has changed from the traditional way, focusing on music technological knowledge, to emphasis on students' feeling, paying attention to students' living, 
interest, feeling and practice with the continuous improvement of the music education development of primary and secondary school. By considering to the practical education problems, music education at present is encouraging students to pursue the creation of aesthetic significance, to enhance their own music accomplishment, and to cultivate excellent ability of music aesthetic experience.

First of all, music is the art of listening, and more importantly, the experience of emotion. The source of music aesthetic experience is diverse, and is obtained in aesthetic experience. In the aesthetic of humanistic psychology, Maslow thought that "the peak experience is most likely to happen in aesthetics, but not only in art and aesthetics. These wonderful moments could be from love, from the combination with the opposite sex, from the aesthetic feelings(especially music), from the creation of impulses and creation of passion and great inspiration, from the great sense of insight and discovery, from the natural delivery of women and the love for children, from the blend with nature(i.e. in the forest, on the beach, in the mountains), from sports, such as snorkeling, from dancing...But no matter where it happens, the peak experience is the same, although the effect of stimulus is different. ${ }^{(1)}$ From Maslow's humanistic psychology, the acquisition of aesthetic experience is from the spark generated by the initial spiritual feelings in the emotional collision, a spiritual aesthetic experience. The cultivation of students' aesthetic feelings, with aesthetics as the core, is to focus on the students' emotional world, to excavate students' real feelings deep inside, to guide students to grasp the emotional connotation of music, and to pay attention to the process of aesthetic experience of music. Different experiencing ways for aesthetic feeling lead to the same aesthetic experience. Therefore cultivation of students' aesthetic experience can use difference teaching methods and different equipment, and guide students to feel different aesthetic contents, but not confined to the old teaching tradition. Different aesthetic contents could touch students' sensitive aesthetic inspiration, stimulate their aesthetic power, and improve their aesthetic ability. The music aesthetic ability should be cultivated step by step, only after a large quantity of systematic training, qualitative changes could happen in the aesthetic ability of music aesthetic experience. Consequently, during the actual teaching, the teacher should help students gain the aesthetic feeling of music culture from surface to depth, and gradually deepen the aesthetic feeling of music and enhance the aesthetic taste, so as to make then better feel the infinite charm of music from their own feelings, and ultimately achieve the goal of music aesthetic education.

\section{Training on Students' Aesthetic Feelings in the Classroom Teaching}

Music class of primary and secondary school is an effective way for the cultivation of students' aesthetic ability. The way of aesthetic feelings cultivation can be divided into two kinds: one is the cultivation of external auditory sensation training, and the other is the inner auditory training. "Music sense of hearing could be interpreted to be the feeling on music, which has two kinds: the external hearing and the inner hearing." "थ Music is a kind of line with liquidity, and also an art of hearing which could enjoy some aesthetic experience. Auditory training is necessary for the cultivation of students' music aesthetic feelings. It means that the students should listen to as many music works as possible, and then think about them; for different musical works have different understanding and judging attitude. Only rely on a large number of external auditory training and listening to music can the students have a certain sense of hearing on music, be touched by the music, and get the sense of aesthetics feeling. For music work, it is not enough for students to know whether it is good or not. Further though on music works are demanded for the real enjoyment and excitement of music aesthetic feeling. You can get different kinds of aesthetic feelings when listening to different styles of music. It will be possible for students to resonate with music from the deep heart, be eager to understand music instinctively, and appreciate and understand music in real by listening to multifaceted music and thought on it. Based on the above, the experience for music aesthetic feeling could be deeply impressed gradate, the aesthetic sense of music could be further improved. 
Music auditory training, a more complex cognitive process, is the foundation of music works understanding, and is basic for the formation of music aesthetic experience ability. Just like vocal music, dance and other courses, auditory training on music needs to have steps and plans. Through rigorous and systematic training on the logic of external auditory and inner music, students are able to improve their own music listening skill with completely understanding of music works and ability to express themselves, so as to obtain the appropriate aesthetic experience of music. From a psychological point of view, hearing is the most important sense next to vision, learning music must have a pair of "musical ears", not only to hear the melody of music, but also to distinguish the rich sensibility and expression in music. During training on external auditory, the students' inner changes in the music world should be considered simultaneously. The students start to understand, to feel and to remember music in heart, once the music beginning. The emotional experience and the perception of music will also be changed with the inner changes, which will produce rich imagination.

\section{Input and Output Ways of Music Aesthetic Feeling}

The aesthetic feeling cultivation of primary and secondary students' is not limited to listening to music, feeling or appreciating music, but what's more, students should learn to express and create music after listening, and to master the cultural knowledge of music. It means that for students' aesthetic feeling education, it is necessary to pay attention to not only ability of feeling and imagining, but also ability of expressing so as to allow students to possess a comprehensive aesthetic capacity of the music culture.

"The way students express their feelings on music is also varied, including performance, painting, speaking, etc. Music teachers should put music feeling and appreciation teaching into music expression and creation in music and the related culture class. The cultivation of the students' feelings and appreciation of the music cannot be realized only through one area. Then the teaching contents should not be confined to the teaching materials, either. Therefore, music teachers must adapt teaching materials to students, flexibly use and re-create them, and introduce the most suitable music

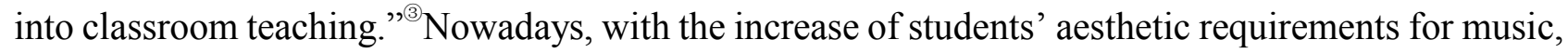
the teachers' educational concept should be gradually improved to adapt to the development of students. How is the student's aesthetic feeling of music reflected? How does the music teacher evaluate student's music aesthetic feeling? How can students get better feeling on music? Many people have not seriously considered the above questions. Teacher's education is usually the single way for the student's music learning, which makes the content be boring, the music aesthetic experience class be dull, the teaching effect fail to meet the requirements, the result be unsatisfied, the input and the output of teaching be unbalanced, and finally result in the student's music aesthetic experience learning stay stagnant.

According to the primary and secondary school music curriculum standards, music aesthetic experience classroom teaching are asked to stimulate students' interest in music learning, to cultivate a good habit of listening to music, and to gradually accumulate experience of music feeling and appreciation, aiming to improve the ability of music aesthetic feeling. Obviously, listening to music is an important way but not the only one to feel and appreciate music. The aesthetic ability of music contains not only the aesthetic experience, but also the aesthetic creation and performance on music, which are two indispensable parts of the integrated music aesthetic ability. Music is a kind of line with liquidity. The expression ability of music students to cultivate the aesthetic ability of music not only to enable students to have is as important as the feeling ability on music in the cultivation for students' music aesthetic feeling ability. The process of music aesthetic experience learning is the same for everybody, no matter for primary school students, junior high school students, adults or singers. Therefore, in the teaching process of music aesthetic experience, it is as important to letting students express music and create music as to listen to music. The teacher should make full use of teaching materials to educate students based on the teaching materials in the field, but with advanced perspective and a higher point of view. In that way, the teacher would avoid to feel isolated in the 
teaching, would know students' music aesthetic feeling in time, would be better and faster to grasp of the development of students' aesthetic ability of music, and then gradually improve students' ability of music aesthetic experience. Therefore, in the process of cultivating students' aesthetic feeling of music, it is necessary to make students take enough music nutrition and guarantee students' to make response to music, which is a natural ecological balance in music aesthetic learning process.

\section{References}

[1] Aesthetics Research Team of Philosophy Department of Peking University. Discussion on beauty and aesthetic feeling by western aesthetic, The Commercial Press, [M]. 1980.

[2] Zhu Fang, Preliminary study on improving students' musical hearing through chorus teaching, [J], Basic Education Research, 2013(the second half).

[3] Guo Sheng-jian, Clarify a few question on music "feelings and appreciation" teaching of primary and secondary school, [J], Curriculum, Teaching Material and Method., 2010(8). 